\title{
The ecological hazard of artificial lighting in greenhouses
}

\author{
Marian Gilewski \\ Faculty of Electrical Engineering, Bialystok University of Technology, Wiejska 45A, 15-351 Bialystok
}

Received September 16, 2019; accepted September 29, 2019; published September 30, 2019

\begin{abstract}
This article draws attention to the shortcomings of modern lighting systems used in greenhouses. Its content focuses on the negative effects of mismatches between the photosynthetic needs of plants and the parameters of artificial light sources. Greenhouse lamps designers often do not have the knowledge of biological cultivation dependencies. Therefore, their cooperation with specialists of plant physiology and gardeners is indispensable. This is important because it can affect the consumer quality of vegetables.
\end{abstract}

People perceive the environment in a selective way, whose boundaries are determined by our visual organ. Moreover, we believe that other participants in the earthly biological life see and should see the environment as we do. In the next step, we ignore the needs of all species of fauna and flora, we design lighting systems adjusted to our eyesight. Finally, we are surprised why some animal species die in automobile accidents [1], birds die after crashing into skyscrapers [2,3] and the greenhouse plants grow slower [4-6] than we expect? After all, we provided white light with a high colour rendering index or selectable colour temperature - but in pursuit of economic efficiency, we have forgotten about nature. This paper describes the aspect of spectral and temporal mismatch of artificial light sources in the greenhouse plants.

The thematic scope of this article covers only the issues of crops lighting and the LED light sources used. In particular, the author of this article wants to pay attention to mistakes made by lamp and lighting system designers. Working under economical pressure, these experienced specialists in commercial lighting, apply their solutions to the greenhouse horticulture.

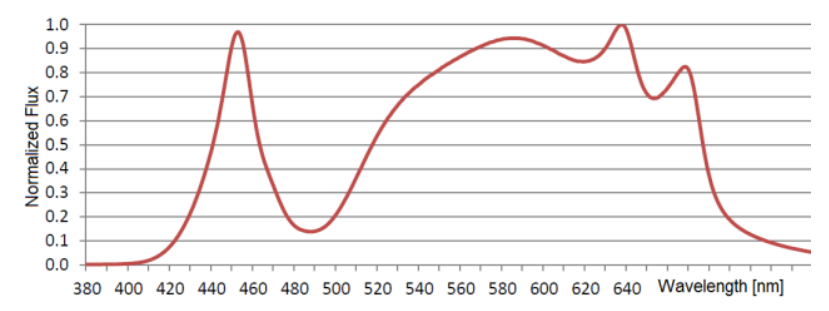

Fig. 1. Spectral power distribution of example FSW lamp [7].

Therefore, LED lighting in horticulture offers so-called Full Spectrum White lamps (FSW, Fig.1). These lamps, according to the designers, should replace or complement the missing solar radiation. You can accept such a thesis if the spectral characteristics of Sunlight (Fig. 2) and FSW lamps did not differ significantly.

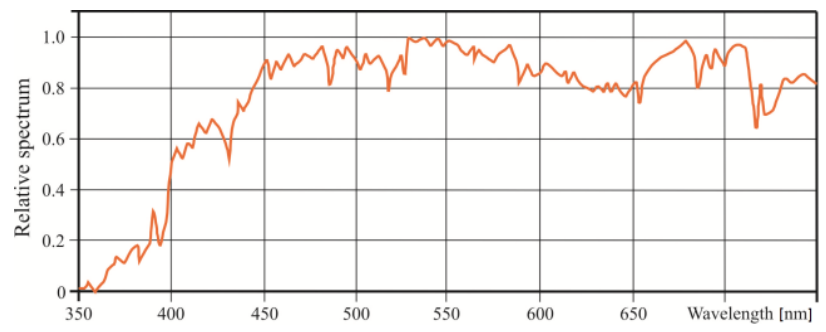

Fig. 2. Example spectral distribution of solar radiation [8].

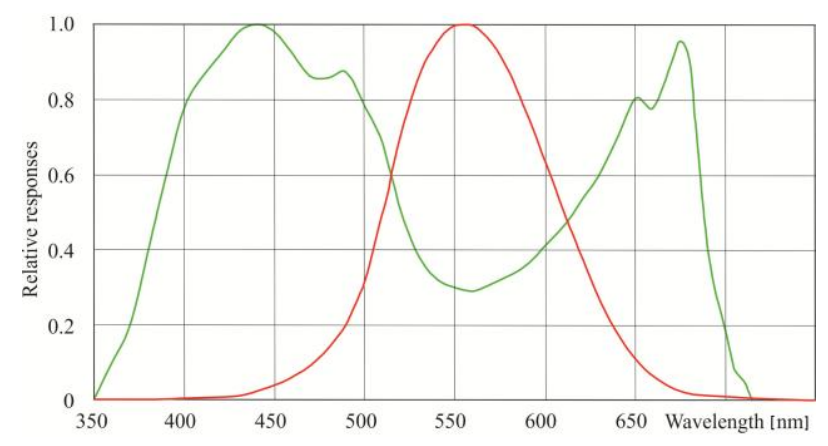

Fig. 3. Characteristics of spectral sensitivity: a human eye (red) and an example PAR curve (green) [9].

Our natural source, the Sun, for millions of years has provided radiation necessary in an evolutionary process. Its rich spectrum covers the needs of all plants and animals, including humans. However, when it comes to spectral distribution, the needs of humans and plants vary considerably. People use the visible radiation range, while plants absorb radiation mainly in a different wavelength range. The equivalent of photopic function $V(\lambda)$ in the plant world are McCree curves [10]. These curves are the averaged functions of measured spectral absorption of 20 plant species. Greenhouse lamp designers often cite the PAR curve (Photosynthetically Active Radiation) [11-12], which is limited to the stimulation of biomass growth in the radiation band from 400 to $700 \mathrm{~nm}$. By comparison of $\mathrm{V}(\lambda)$ and PAR curve (Fig. 3) you will see their spectral incompatibility. Thus, the use of FSW lamps (Fig. 1) to illuminate plants is a mistake in horticultural art. Another 
negative consequence is the designing energy-efficient orientation, which aims only to stimulate the biomass growth, according to the chlorophylic PAR curves [13]. Designers often use the concepts of McCree and PAR as equivalent (Fig. 4).

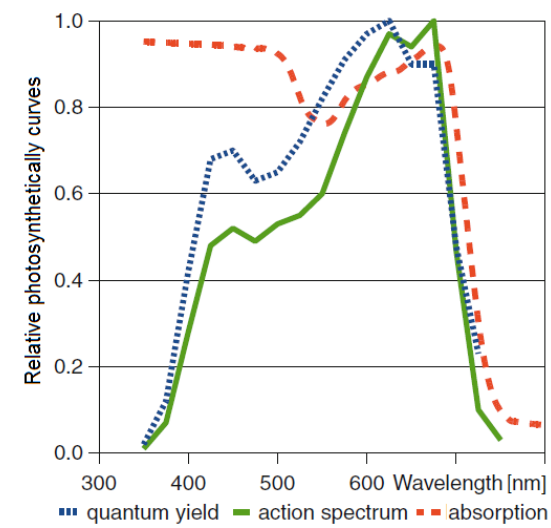

Fig. 4. Spectral plant sensitivities [14]

In practice, it does not actually synthesize even the characteristics of PAR, minimizing the number of spectral lamp channels synthesized even the characteristics of PAR, minimizing the number of spectral lamp channels. In the simplest case, you use four types of spectrally different LEDs to build greenhouse lamps. As a result (Fig. 5), the spectral emission characteristics of the lamp differs from the expected PAR curves. More spectral flexibility is offered by the structures that contain 9 and more spectral bands.

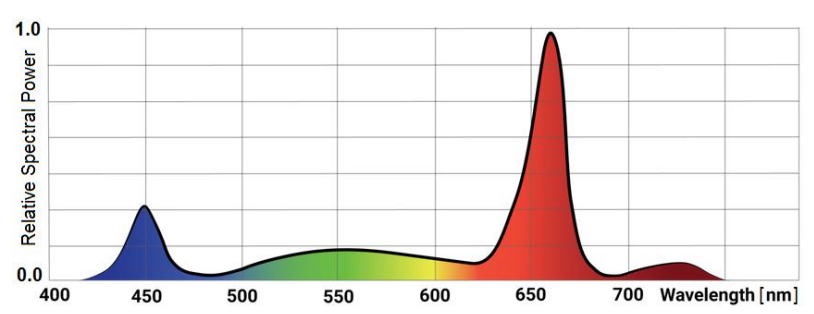

Fig. 5. Sample spectral emissive characteristics of four-channel (450 $\mathrm{nm}, 660 \mathrm{~nm}, 735 \mathrm{~nm}$ and $5700 \mathrm{~K}$ white) greenhouse lamp [15].

However, these are expensive solutions, designed for scientific research [16] rather than for the use in greenhouse lighting systems.

The greater the number of spectral bands, the greater the quality of the spectral synthesis of the lamp characteristics. However, the economic factor restricts the flexibility of development by limiting the synthesis of spectral characteristics to approximated chlorophylic curves. Falling into traps of energy efficiency and versatility, we forget the biological conditions of crops. And after all, each plant needs a different spectral radiation in various vegetative phases. Moreover, each monoculture has its own set of biological performance curves (Fig. 6). The awareness of these conditions is not widespread among designers and manufacturers of greenhouse lamps.

The lack of horticultural knowledge or substantive support by plant physiologists causes structural errors in lighting control systems. Plants are not able to absorb excessive or poorly chosen spectral lighting. In such a situation, the vegetation process slows down and in the extreme case, it is stopped. We all see night-lighted greengrocers that produce vegetables. As engineers, we recognise such a condition as normal, even desirable, as it means efficient use of technical systems. We do not think that plants like humans need night (darkness) for regeneration and growth. The daily and monthly cycle (Fotoperiod) is also very important in the world of plants [17-19]. The length and cyclicality of night are biological parameters of the clock synchronizing plant growth. It is disturbed by excessive and poor lighting, creating a "light pollution" effect in the plant environment.

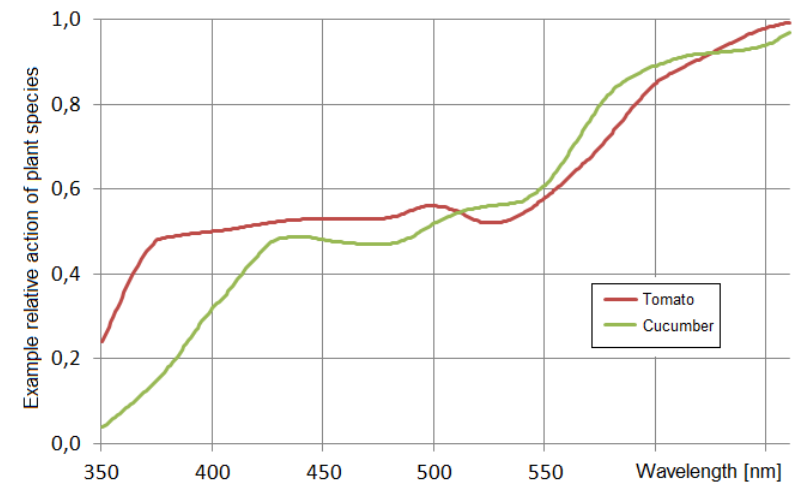

Fig. 6. Sample action spectra of selected greenhouse monocultures.

Artificial glass lighting can introduce one more harmful component of light pollution. It is a pulse control of the LEDs power [20-23] in the greenhouse lamps. It is a very popular way in energy-electronics of controlling the source of power, optical power including [24-25]. What's more, it is expected that plants in a similar way as human average the flickering light above the fusion frequency.

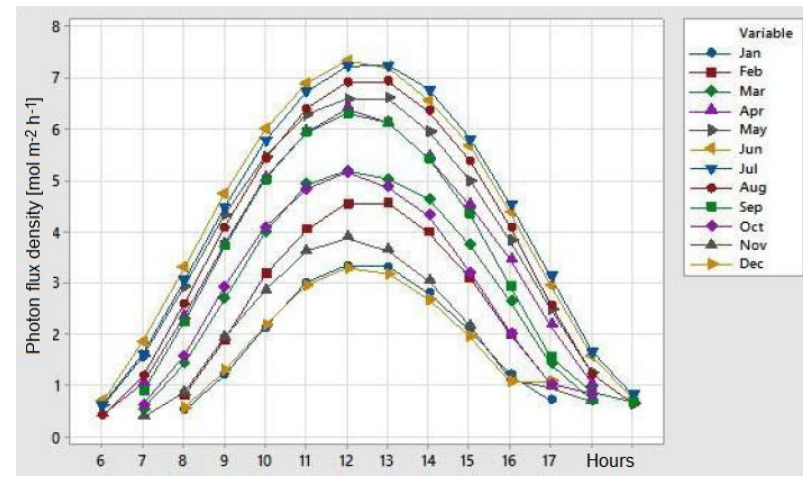


Fig. 7. Daily and monthly cycle of solar activity [26].

In nature, the flux of natural solar radiation varies very slowly during the day and year (Fig. 7). These changes never occur at a frequency of $10 \mathrm{kHz}$, as it is in a pulsecontrolled LED matrix (Fig. 8). As apparent from the existing studies, pulsating radiation differently affects plant vegetation than continuous radiation [27-28].

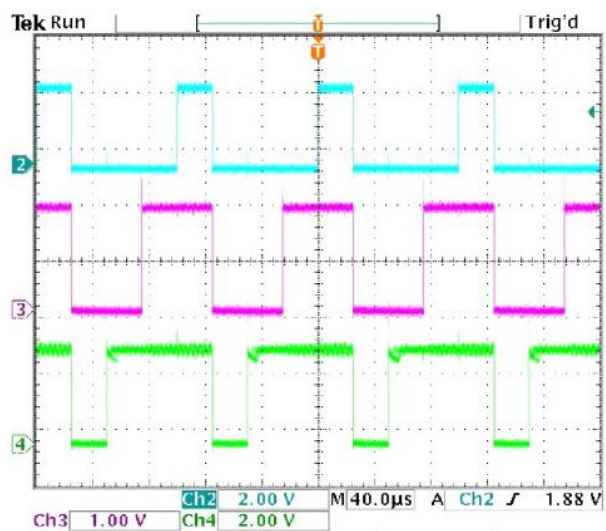

Fig. 8. Pulse driving RGB LEDs in additive synthesis

In conclusion, it is worth to note that additional lighting in greenhouses accelerates the growing process, resulting in biomass growth. However, improperly selected spectral composition of artificial lighting and photoperiod can: reduce the efficiency of the system, degrade the consumer quality of vegetables or reduce the resistance of seedlings. It is obvious that negative climate changes will force us to move open crops to the greenhouses. However, I hope that technical innovations in lighting will considerably improve the quality of yields rather than maximize the economic effect.

\section{References}

[1] M.Kucharczyk, I.Gąsak, Ecological effects of light pollution, III Internat. Conf. on Scientific and Technical TRANSEIA, Krynica Zdrój, Poland 2017.

[2] T.H. Goldsmith, What Birds See (Scientific American Inc. 2006), available: www.sciam.com.

[3] E.J. Gerl, M.R. Morris, The Causes and Consequences of Color Vision (Springer Science + Business Media, LLC 2008).

[4] K. Jaworski, A. Szmidt-Jaworska, J. Kopcewicz, Two calcium dependent protein kinases are differently regulated by light and have different activity patterns during seedling growth in Pharbitis nil, open access at Springerlink.com, Journal: 10725, Article: 9609, 2011.

[5] K. Jaworski, A. Pawełek, J. Kopcewicz, A. Szmidt-Jaworska, J. Plant Physiol. 169, 1578 (2012).

[6] A. Szmidt-Jaworska, K. Jaworski, J. Kopcewicz, J. Photochemistry and Photobiology B: Biology 93, 9 (2008).

[7] Horticulture Lighting Group, Goniophotometer Test Report of the ELITE ECO lamp, available: https://horticulturelightinggroup.com/ collections/lamps/products/elite-360-eco.

[8] K. Marra, E.P. LaRochelle, M.S. Chapman, P.J. Hoopes, K. Lukovits, E.V. Maytin, T. Hasan, B.W. Pogue, Comparison of Blue and White Lamp Light with Sunlight for Daylight-Mediated, 5-ALA
Photodynamic Therapy, in vivo, Wiley Online Library, 16 April 2018, Available: https://doi.org/10.1111/php.12923.

[9] M. Gilewski, The Ecological Harmfulness of RGB LED Light, Internat. Conference on Energy, Power, Electrical and Environmental Eng.: EPEEE 2018, DEStech Publications, Wuhan, Hong Kong, September 2018.

[10] K. J. McCree, The Action Spectrum, Absorptance and Quantum Yield of Photosynthesis in Crop Plants, Agricultural Meteorology (Elsevier Publishing Company 1972, p. 191-216).

[11] EconoLux Indastries Ltd., What Light do Plants Need, Hong Kong, available: http://econoluxindustries.com/light-plants-need.html.

[12] I. Ashdown, Photometry and Photosynthesis: From Photometry to PPFD, SunTracker Technologies Ltd., available: https://www. researchgate.net/publication/284157299.

[13] OSRAM Opto Semiconductors, Horticulture Lighting with LEDs, OS SSL | NR AW CH, November 2016, avaliable: www.osram.com.

[14] M. Mottus, M. Sulev, F. Baret, R. Lopez-Lozano, A. Reinart, Photosynthetically Active Radiation: Measurement and Modeling, available: https://www.researchgate.net/publication/281510241.

[15] Heliospectra AB, Full Flexibility ELIXIA grow light, available: https://www.heliospectra.com/led-grow-lights/commercial-led-growlights/

[16] Heliospectra AB, Full Flexibility ELIXIA grow light, available: https://www.heliospectra.com/led-grow-lights/commercial-led-growlights/.

[17] A. Szmidt-Jaworska, K. Jaworski, A. Tretyn, J. Kopcewicz, J. Plant Physiol. 161, 277 (2004).

[18] A. Szmidt-Jaworska, K. Jaworski, J. Kopcewicz, J. Plant Growth Regul. 25, 233 (2006)

[19] A. Szmidt-Jaworska, K. Jaworski, A. Zienkiewicz, M. Lenartowska, J. Kopcewicz, Plant Growth Regul. 57,173 (2009).

[20] U.J. Błaszczak, D.A. Aziz, L. Gryko, Proc. SPIE 10445, 1 (2017).

[21] L. Gryko, U. Blaszczak, A.S. Zajac, Proc. SPIE 10808, 1080811 (2018).

[22] I. Fryc, T. Dimitrova-Grekow, An automated system for evaluation of the quality of light sources, 6th IEEE Lighting Conference of the Visegrad Countries : LUMEN V4, Karpacz, Poland 2016.

[23] J. Kusznier, M. Zajkowski, L. Budzynski, D. Tyniecki, SPIE 10325, 10325-23 (2017).

[24] W. Wojtkowski, LED Power Supply with Thermal Protection for Automotive Application, 7th Lighting Conference of the Visegrad Countries : LUMEN V4, Třebíč 2018.

[25] W. Wojtkowski, Constant Frequency Operation of the Parallel Loaded Resonant DC/DC Converter for Power LED Lighting, Internat. Conference on Energy, Power, Electrical and Environmental Engineering: EPEEE 2018, Hong Kong 2018.

[26] S. Pashiardis, S.A. Kalogirou, A. Pelengaris, J. Biometrics Biostat. 2(2), 1009 (2017).

[27] R. Inger, J. Bennie, T.W. Davies, K.J. Gaston, PLoS One 9(5) PMC4038456 (2014), available: https://www.ncbi.nlm.nih.gov/ pmc/articles/PMC4038456/\#pone.0098631-Renner1/.

[28] C. Dong, Y. Fu, G. Liu, H. Liu, Growth, photosynthetic characteristics, antioxidant capacity and biomass yield and quality of wheat (Triticum aestivum L.) exposed to LED light sources with different spectra combinations, J. Agron. Crop. Scien. 200, 219 (2014). 